12,18

\title{
Функционализация индивидуальных МУНТ при облучении и отжиге
}

\author{
(C) В.В. Болотов, Е.В. Князев , П.М. Корусенко, С.Н. Несов, В.А. Сачков \\ Омский научный центр СО РАН, \\ Омск, Россия \\ 『 E-mail: knyazev@obisp.oscsbras.ru
}

Поступила в Редакцию 11 июня 2020 г.

В окончательной редакции 11 июня 2020 г.

Принята к публикации 24 июня 2020 г.

\begin{abstract}
Методами просвечивающей электронной микроскопии и рентгеновской фотоэлектронной спектроскопии исследована структура индивидуальных многостенных углеродных нанотрубок, подверженных облучению потоком ионов аргона и электронов, а также последующим термообработкам в инертной среде. Показано, что облучение ионами аргона и электронами приводит к образованию дефектов в структуре углеродных нанотрубок и изменению межслоевого расстояния в стенках нанотрубок, и закреплению на их поверхности функциональных кислородсодержащих групп. Отжиг в инертной атмосфере предварительно облученных нанотрубок приводит к частичному восстановлению структуры МУНТ. При этом в случае облучения ионами аргона наблюдается восстановление структуры нанотрубок и уменьшение концентрации кислорода. В случае облучения электронами после отжига образуются протяженные мультивакансионные дефекты, на которых формируются функциональные группы, содержащие двойную химическую связь углерода и кислорода $(\mathrm{C}=\mathrm{O})$. С помощью расчетов, проведенных в рамках теории функционала плотности, получены значения энергии связи и оптимизированная геометрия для различных конфигураций вакансионных кластеров в графеновой плоскости.
\end{abstract}

Ключевые слова: электронная микроскопия, рентгеновская фотоэлектронная спектроскопия, многостенные углеродные нанотрубки трубки, облучение заряженными частицами, отжиг в инертной среде, функционализация.

DOI: 10.21883/FTT.2020.11.50072.125

\section{1. Введение}

Многостенные углеродные нанотрубки (МУНТ) представляют собой 1D-структуру из коаксиально свернутых графеновых слоев. Высокая механическая прочность, большая площадь поверхности, широкий диапазон электропроводности делают возможным использование МУНТ в качестве материалов для создания газовых наносенсоров, элементов литий-ионных аккумуляторов, суперконденсаторов и т.д. [1-3]. В зависимости от конкретной области применения меняются требования к структуре и физико-химическим свойствам МУНТ. Однако синтез нанотрубок с заданным набором свойств остается сложной задачей, что вызывает необходимость разработки методов управления физико-химическими свойствами МУНТ для получения оптимальных характеристик приборов и устройств на их основе. Применение методов функционализации МУНТ позволяет модифицировать структуру углеродных нанотрубок, что дает возможность оптимизировать набор физико-химических характеристик для каждого конкретного применения.

Поскольку внутренняя структура определяет электрофизические, механические, а также сорбционные свойства нанотрубок, то ее трансформацией можно добиться изменения свойств МУНТ и их ансамблей. Достаточно эффективным способом влияния на структуру углеродных нанотрубок является облучение потоками заряженных частиц $[4,5]$.
Основным видом дефектов, образующихся в результате облучения заряженными частицами, являются вакансии и междоузельные атомы в графеновых слоях МУНТ. При этом в случае воздействия относительно тяжелых ионов типа $\mathrm{Ar}^{+}$могут формироваться протяженные дефекты с образованием мультивакансионных кластеров и аморфизованными участками стенок МУНТ [6,7]. Особенностью облучения электронами является более щадящее воздействие на структуру углеродных нанотрубок, поскольку при этом формируются в основном точечные дефекты - вакансии и междоузельные атомы в графеновых стенках МУНТ, а также топологические дефекты образованные поворотом $\mathrm{C}-\mathrm{C}$-связи (SW-дефекты) [6]. Формирование дефектов, в результате облучения, приводит к изменению взаимодействия между графеновыми слоями МУНТ [7-9]. Отжиг в инертной атмосфере приводит к аннигиляции точечных дефектов, однако, при больших концентрациях дефектов может наблюдаться неполное восстановление структуры нанотрубок с образованием стабильных дефектных областей в стенке нанотрубки [10]. Такие области способны оказывать существенное влияние на электрофизические свойства нанотрубок и их ансамблей [11].

В настоящей работе методами просвечивающей электронной микроскопии (ПЭМ) и рентгеновской фотоэлектронной спектроскопии (РФЭС) исследованы структурные изменения МУНТ, подверженных облучению 
ионами $\mathrm{Ar}^{+}$, с энергией $300 \mathrm{keV}$ и флюенсом $10^{12} \mathrm{~cm}^{-2}$, a также электронами с энергией $3 \mathrm{MeV}$ и флюенсом $10^{16} \mathrm{~cm}^{-2}$. Кроме того, исследована трансформация структуры облученных МУНТ при последующем отжиге в инертной атмосфере аргона при температуpe $900^{\circ} \mathrm{C}$. С целью детализации радиационно-стимулированных процессов дефектообразования применялось численное моделирование в рамках теории функционала плотности (DFT), для определения параметров геометрии элементарной ячейки при наличии значительных концентраций вакансий.

\section{2. Методика эксперимента}

В работе исследовались углеродные трубки, синтезированные методом каталитического осаждения из газовой фазы (CVD). Источником углерода служил ацетонитрил, температура реакции составляла $800^{\circ} \mathrm{C}$. В качестве катализатора роста МУНТ выступали наночастицы железа, образующиеся при термическом разложении ферроцена, входящего в реакционную смесь. В качестве транспортного газа для поставки углеводородного и железосодержащего сырья в зону реакции CVD-реактора применялся ОСЧ аргон марки 6.0. Рост слоя МУНТ происходил на подложках $\mathrm{Si} / \mathrm{SiO}_{2}$. Полученные нанотрубки были легированы азотом на уровне $2-3$ at. $\%[2,4,9]$.

Слои МУНТ после синтеза подвергались термообработке на воздухе при температуре $390^{\circ} \mathrm{C}$ в течение 120 min для очистки от загрязнений: аморфного и нанокристаллического углерода, неразложившихся углеводородов, образующихся в процессе синтеза. Поскольку особенностью синтеза МУНТ методом каталитического осаждения является постоянная подача в реактор смеси ацетонитрилла и ферроцена на внешней поверхности МУНТ могут осаждаться частицы железа не участвующие в росте новых нанотрубок. Для удаления остатков катализатора после термической обработки проводилась химическая очистка образцов в $40 \%$ растворе $\mathrm{HCl}$ в течение $24 \mathrm{~h}$ [9].

Для радиационных обработок подготавливались ансамбли индивидуальных нанотрубок. Синтезированные и очищенные МУНТ диспергировались ультразвуком в этаноле и полученная суспензия наносилась аэрозольным методом на поверхность окисленного монокристаллического кремния. В результате были получены слои индивидуальных МУНТ, расположенных преимущественно параллельно подложке.

Далее ансамбли МУНТ подвергались облучению электронами с энергией $3 \mathrm{MeV}$, и флюенсом пучка $10^{16} \mathrm{~cm}^{-2}$, a также ионами $\mathrm{Ar}^{+}$с энергией $300 \mathrm{keV}$ и флюенсом пучка $10^{12} \mathrm{~cm}^{-2}$. Пучки частиц направлялись нормально к поверхности образцов. После радиационной обработки МУНТ подвергались отжигу при температуре $900^{\circ} \mathrm{C}$ в течение $30 \mathrm{~min}$ в атмосфере аргона.

Исследования в ПЭМ производились на микроскопе JEOL 2100 (ускоряющее напряжение $200 \mathrm{keV}$ ). Ис- следования структуры МУНТ выполнялись на оборудовании Омского центра коллективного пользования (ОНЦ СО РАН).

Электронная структура МУНТ до и после ионной и термической обработок исследовалась с использованием рентгеновской фотоэлектронной спектроскопии с применением установки Surface Science Center (Riber). Для возбуждения рентгеновского излучения использовался источник с Al-анодом с энергией линии $\mathrm{Al}$ равной $1486.6 \mathrm{eV}$. Спектры РФЭС измерялись в условиях сверхвысокого вакуума ( 10 $10^{-9}$ Torr) с использованием анализатора МАС-2. Диаметр рентгеновского пучка составлял $\sim 3 \mathrm{~mm}$, мощность источника - $240 \mathrm{~W}$. Разрешение по энергии при регистрации спектров остовных линий составляло $\sim 0.2 \mathrm{eV}$, обзорных спектров $\sim 1.2 \mathrm{eV}$. Глубина анализа данным методом составляла $\sim 3 \mathrm{~nm}$.

Расчеты по оптимизации геометрии элементарной ячейки проводились методом плоских волн в рамках обобщенного градиентного приближения (generalized gradient approximation, GGA) теории функционала плотности (density functional theory, DFT), который является одним из наиболее часто используемых для расчетов методов „ab initio“. В качестве функционала плотности использовался функционал Perdew, Burke, Ernzerhof адаптированный для твердых тел (PBE for solids) [12]. Для расчетов всех исследуемых объектов использовался одинаковый базис электронных функций. Плоская 2D-структура моделировалась из трехмерной путем увеличения периода решетки в направлении перпендикулярном плоскости до $15 \AA$.

\section{3. Результаты и обсуждение}

\section{1. Исследования в ПЭМ}

Согласно данным ПЭМ, исходные МУНТ обладают бамбукоподобной структурой, характерной для азот-легированных нанотрубок (рис. 1) [2,4,9]. Внешний диаметр углеродных нанотрубок варьируется в диапазоне от 20 до $60 \mathrm{~nm}$. Межплоскостное расстояние между графеновыми слоями в стенках исходных МУНТ, полученное по результатам быстрого Фурье-анализа изображений, составляет $\sim 0.34-0.35 \mathrm{~nm}$, что соответствует значению межплоскостного расстояния для МУНТ. Поскольку для пробоподготовки МУНТ к облучению проводилась химическая очистка в 40\% растворе $\mathrm{HCl}$, на внешней поверхности МУНТ наблюдаются кратеры размером до $10-15 \mathrm{~nm}$, образовавшиеся, по-видимому, после удаления частиц катализатора.

Степень воздействия на структуру вещества радиационным облучением существенно зависит от массы заряженных частиц. Обладая малой массой, электроны приводят к формированию в структуре стенках нанотрубок преимущественно точечных дефектов $[6,7]$.

После облучения потоком электронов $(E=3 \mathrm{MeV}$, флюенс $10^{16} \mathrm{~cm}^{-2}$ ), структура графеновых слоев стенок МУНТ видоизменилась (рис. 2). Внешние графеновые 

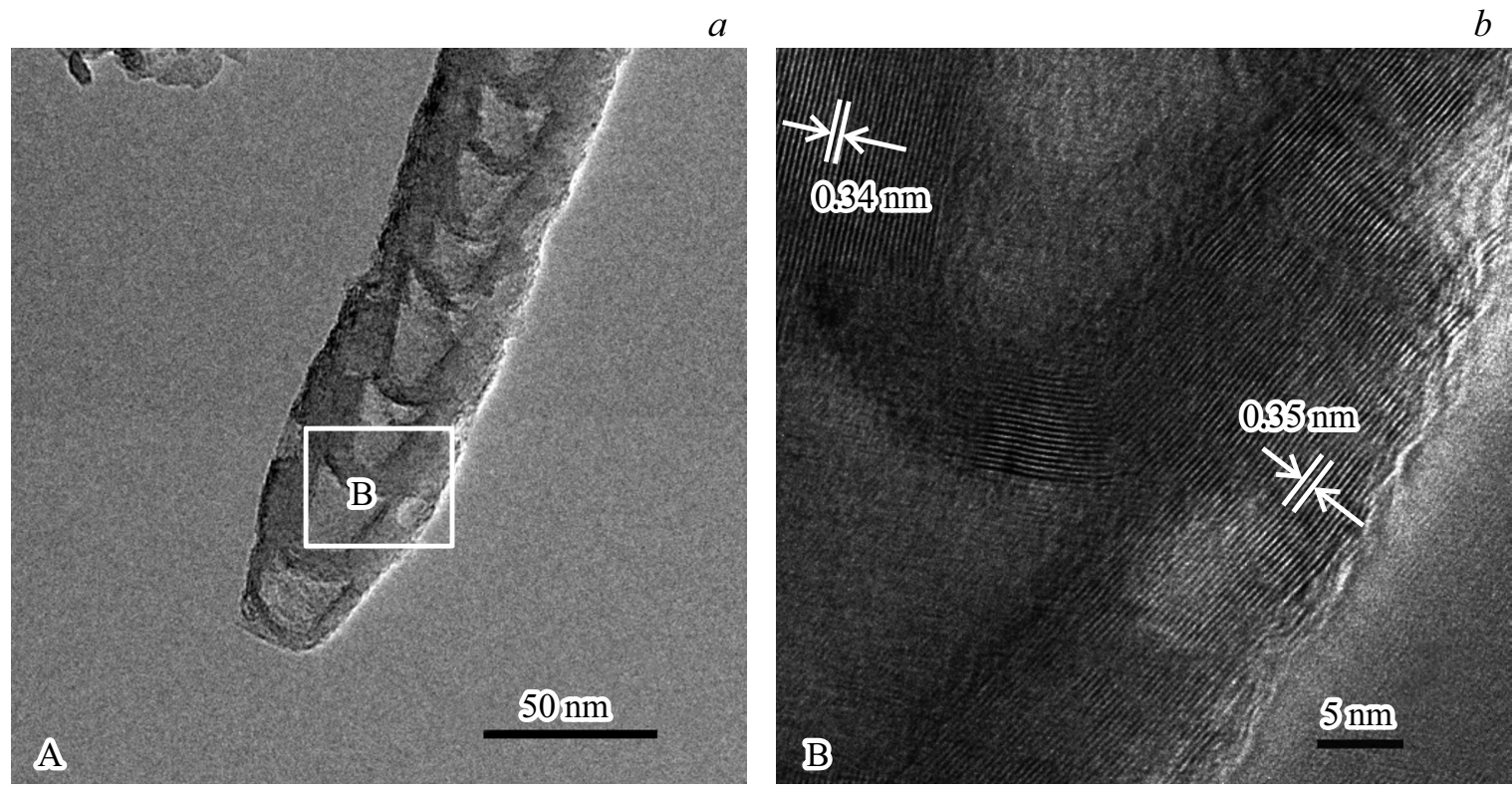

Pис. 1. ПЭМ-изображения: (a) - исходные МУНТ после выдерживания в $\mathrm{HCl} ;(b)$ - область В, выделенная на части $(a)$.
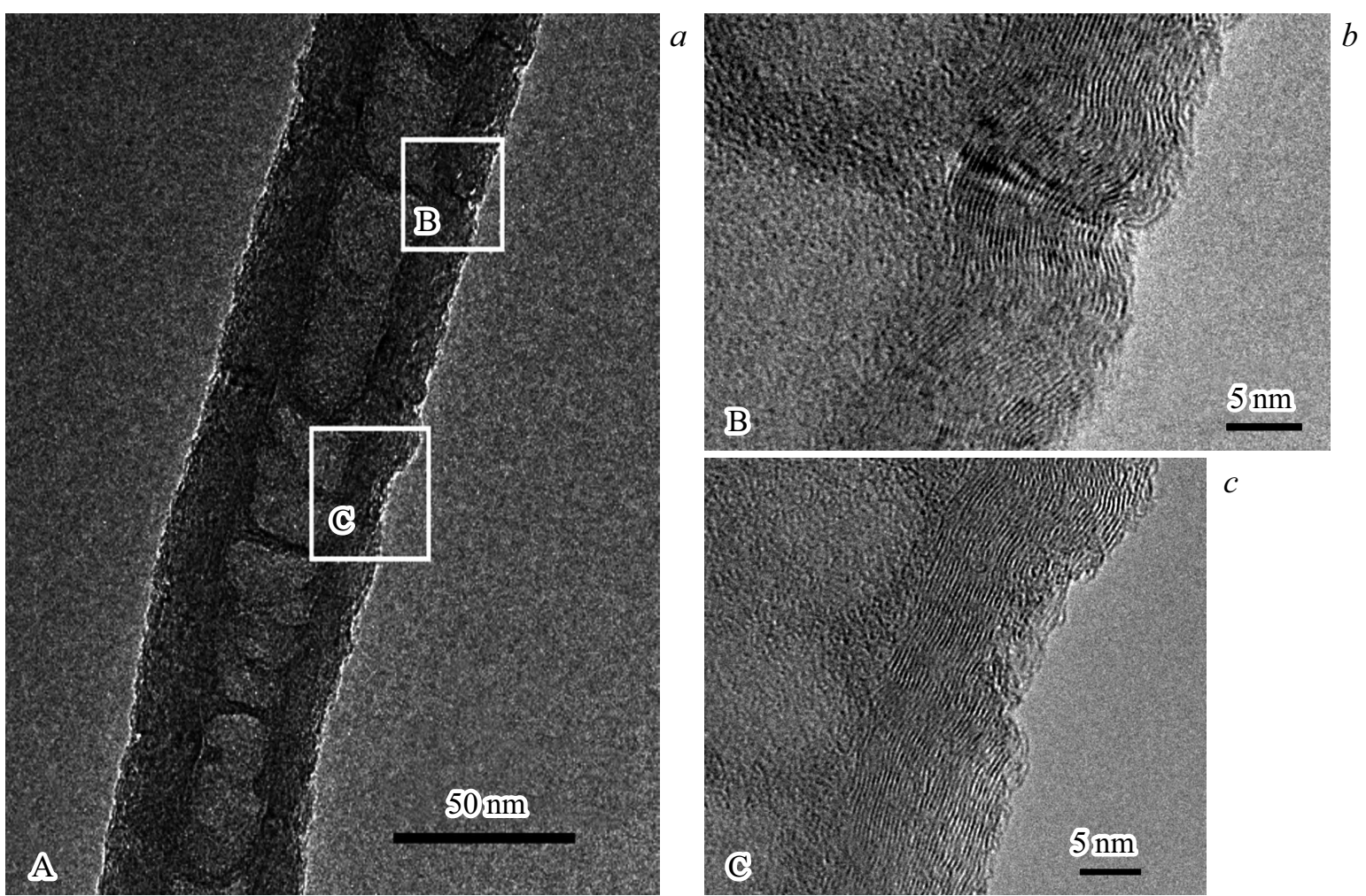

Рис. 2. ПЭМ-изображения: $(a)-$ МУНТ после облучения $\mathrm{e}^{-} E=3 \mathrm{MeV}, 10^{16} \mathrm{~cm}^{-2} ;(b)-$ изгиб графеновых слоев стенки МУНТ, область В, выделенная в части $(a)$; $(c)$ - разрыв внешних графеновых слоев стенки МУНТ, область С, выделенная в части $(a)$.

слои имеют разрывы и искривления (рис. 2,c). В ряде случаев наблюдаются протяженные дефекты, затрагивающие всю толщину стенки нанотрубки (рис. $2, b$ ).

Расчеты межслоевого расстояния, проведенные методом быстрого Фурье-преобразования, показали что, после облучения наблюдается изменение межплоскостного расстояния в стенках МУНТ $-\mathrm{c} \sim 0.34-0.35 \mathrm{~nm}$ в исходных МУНТ до $\sim 0.36-0.38 \mathrm{~nm}$. Увеличение межплоскостного расстояния может свидетельствовать об изменении межслоевого взаимодействия вследствие 
$a$

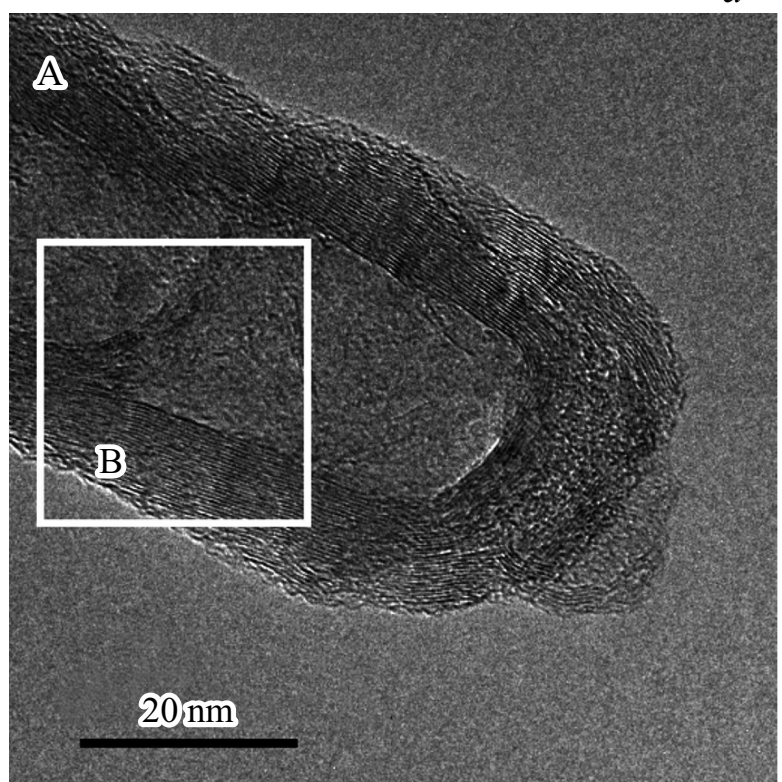

$b$

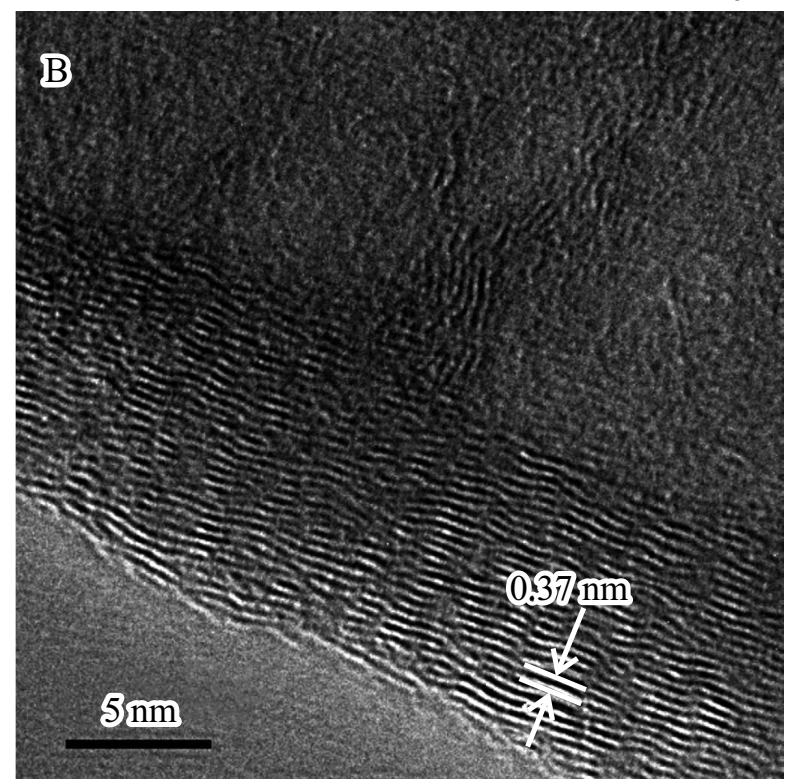

Рис. 3. ПЭМ-изображения: $(a)-$ МУНТ после облучения $\mathrm{Ar}^{+} E=300 \mathrm{keV}, 10^{12} \mathrm{~cm}^{-2}$; $(b)$ - область В, выделенная на части $(a)$.

формирования точечных дефектов в структуре графеновых слоев стенок МУНТ.

При облучении углеродных нанотрубок пучком ионов $\mathrm{Ar}^{+}$с энергией $E=300 \mathrm{keV}$ и флюенсом пучка $10^{12} \mathrm{~cm}^{-2}$ наблюдается частичная аморфизация стенок нанотрубок. Графеновые слои стенки МУНТ выглядят изогнутыми и разориентированными, наблюдаются протяженные дефекты в структуре МУНТ. Межплоскостное расстояние в трубке по данным быстрого Фурье-преобразования составляет $\sim 0.37 \mathrm{~nm}$ (рис. $3, b$ ).

Отжиг в инертной среде предварительно облученных электронами МУНТ приводит к существенным изменениям их структуры. Стенки МУНТ имеют множество разориентированных участков (рис. 4). Во внешних графеновых слоях встречаются разрывы, захватывающие 1-5 графеновых слоев вглубь стенки. Размеры разрывов составляют $\sim 1-4 \mathrm{~nm}$, что значительно меньше кратеров, образующихся при химической очистке материала (рис. 4,c,d). Внешние границы нанотрубок принимают вид ломаной кривой. Помимо локальных дефектных участков стенки, затрагивающих несколько графеновых слоев, присутствуют изгибы стенки МУНТ целиком (рис. 4,d). В целом, структура стенок МУНТ выглядит более разориентированной по сравнению с таковыми до отжига. Особенностью структуры МУНТ после отжига является увеличение межслоевого расстояния у границ кратеров во внешних слоях МУНТ до $\sim 0.39 \mathrm{~nm}$. При этом на остальных участках стенок МУНТ значение межслоевое расстояния $\sim 0.34-0.35 \mathrm{~nm}$.

Отжиг в инертной среде приводит к частичному восстановлению структуры графеновых слоев $[13,14]$. Однако ввиду большого количества точечных дефектов в стенках облученных МУНТ в силу высокого флюенса при отжиге протекают одновременно два процесса: рекомбинация вакансионных дефектов и междоузельных атомов углерода, и образование мультивакансионных кластеров при слиянии моновакансий $[15,16]$. Образование мультивакансионных кластеров во внешних графеновых слоях проявляется в виде формирования малоразмерных кратеров, в то время как вакансии во внутренних графеновых слоях МУНТ, могут приводить к изгибу стенки нанотрубки [17]. Увеличение межслоевого расстояния графеновых слоев в области кратеров, вероятно, объясняется ослаблением межслоевого взаимодействия углеродных атомов с оборванными связями на границе кратеров.

МУНТ, подвергнутые облучению ионами аргона, после отжига в инертной среде частично восстанавливают свою структуру (рис. 5). Графеновые слои стенки нанотрубки принимают вид схожий с необлученными образцами. Однако наблюдаются дефекты, представляющие собой искривление как нескольких графеновых слоев, так и в целом стенки МУНТ. Также необходимо отметить, что восстановление структуры МУНТ с большим количеством графеновых слоев проходит более эффективно, по сравнению трубками, содержащими малое количество графеновых слоев (рис. 5, $b$ и $c$ ). Отсутствие большого количества крупных вакансионных дефектов для МУНТ прошедших облучение $\mathrm{Ar}^{+}$и отжиг при температуре $900^{\circ} \mathrm{C}$ обусловлено отличием механизма дефектообразования и последующей перестройки структуры в процессе термообработки. Относительно тяжелые ионы аргона способны образовывать в структуре нанотрубки каскады смещений атомов. При этом в достаточно небольшой области стенки МУНТ образуется значительная кон- 


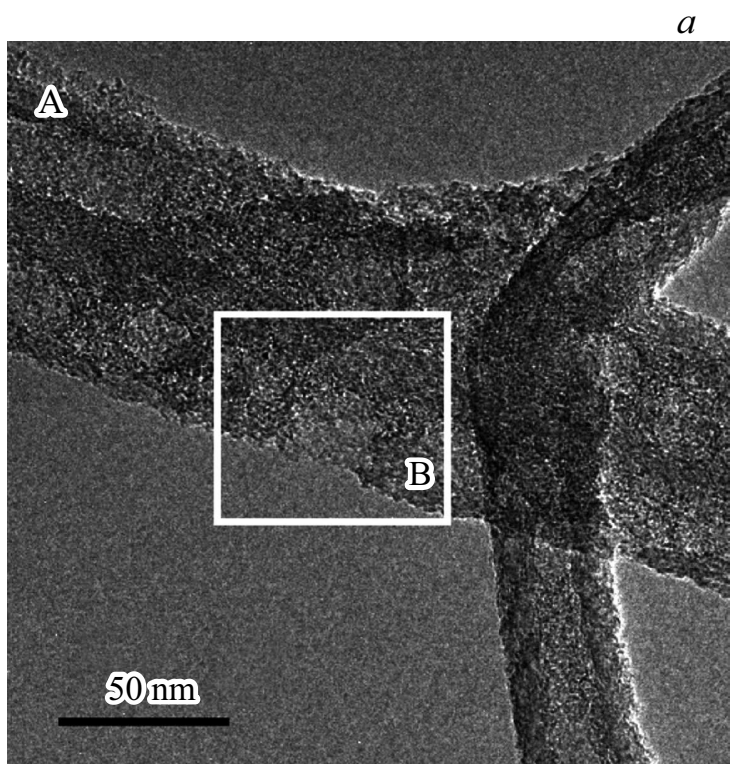

$c$

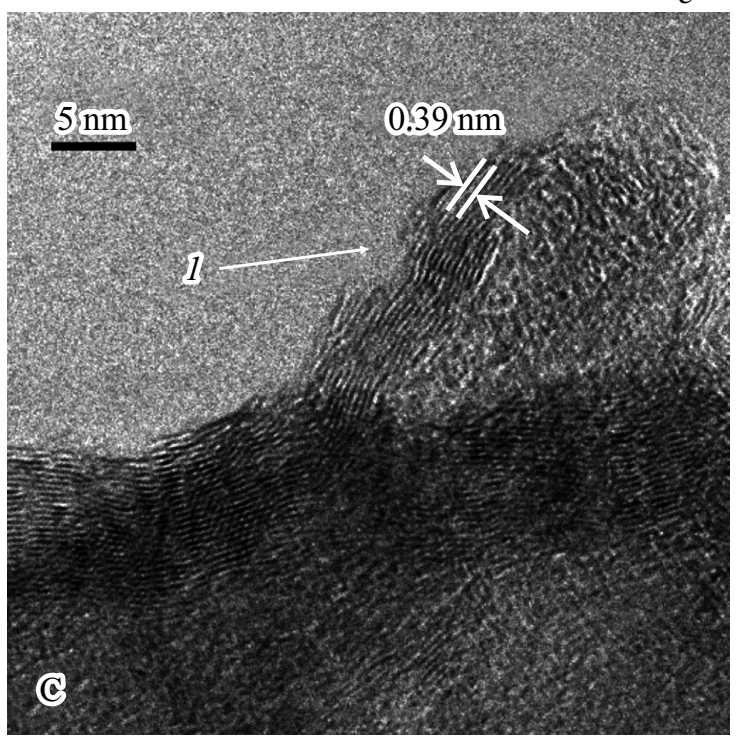

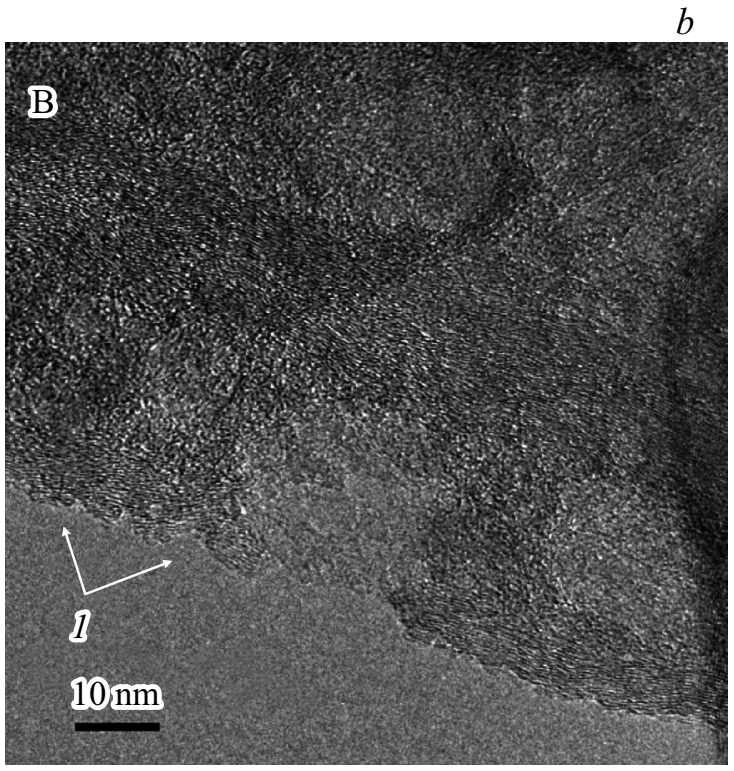

$d$

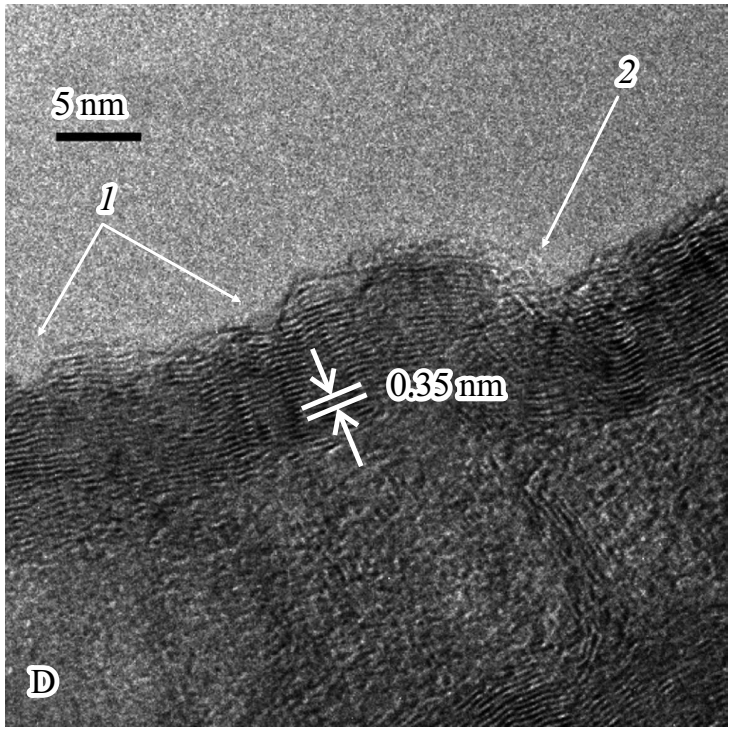

Рис. 4. ПЭМ-изображения: (a) - МУНТ после облучения $\mathrm{e}^{-} E=3 \mathrm{MeV}, 10^{16} \mathrm{~cm}^{-2}$ и последующего отжига в инертной атмосфере при $900^{\circ} \mathrm{C} ;(b)$ - область В, выделенная на части $(a) ;(c)$ - фрагмент МУНТ, содержащий разрыв внешних графеновых слоев стенки нанотрубки; $(d)$ - фрагмент МУНТ, содержащий изгиб стенки нанотрубки. Цифрами обозначены: 1 - разрывы внешних графеновых слоев стенки МУНТ образовавшиеся вследствие электронной и термической обработок; 2 - изгибы стенки МУНТ.

центрация вакансий и междоузлий. С учетом низкого флюенса, можно заключить, что данные области не пересекаются. Отжиг при температуре $900^{\circ} \mathrm{C}$ приводит к аннигиляции точечных дефектов расположенных на небольшом расстоянии друг от друга в области каскада смещения

\section{2. Моделирование структуры графена с высокой концентрацией вакансий}

Для теоретического моделирования мультивакансионных дефектов в графеновом листе первоначально рассчитывались геометрические характеристики минимально ортогонального периодического фрагмента решетки графена. После чего, из полученного графенового листа удалялись атомы углерода, при этом проводились процедуры численной оптимизации структуры с вакансионным кластером. На рис. 6 представлены изображения фрагментов оптимизированной структуры графеновой плоскости с дефектами типа вакансия.

Для структур с вакансионными дефектами рассчитывалась удельная энергия связи $\left(E^{b}\right)$ и значение корругации графеновой плоскости $h_{c}$, которое рассчитывалась как разность координат наиболее отдаленных от плос- 


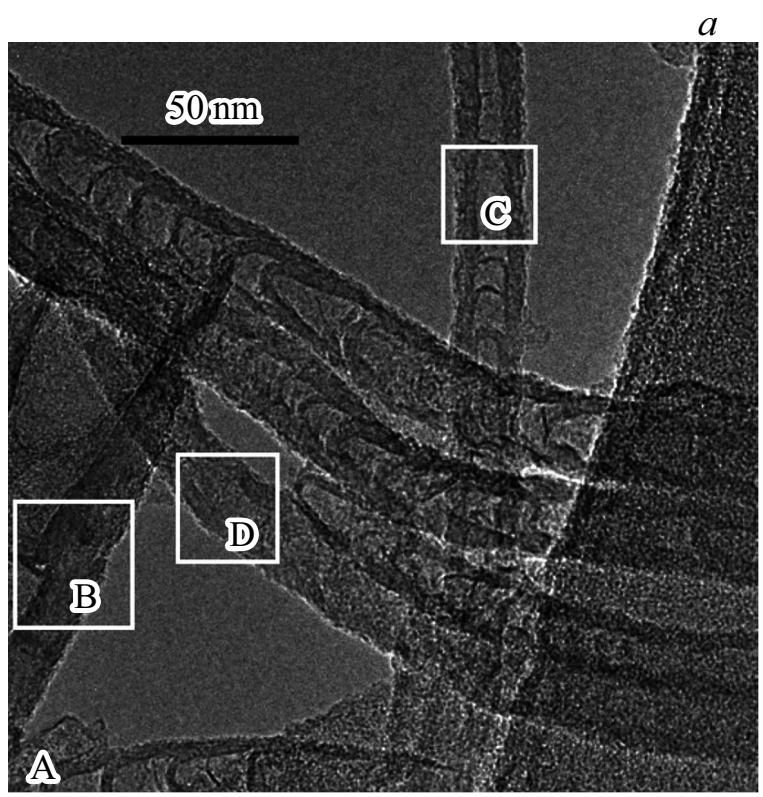

C

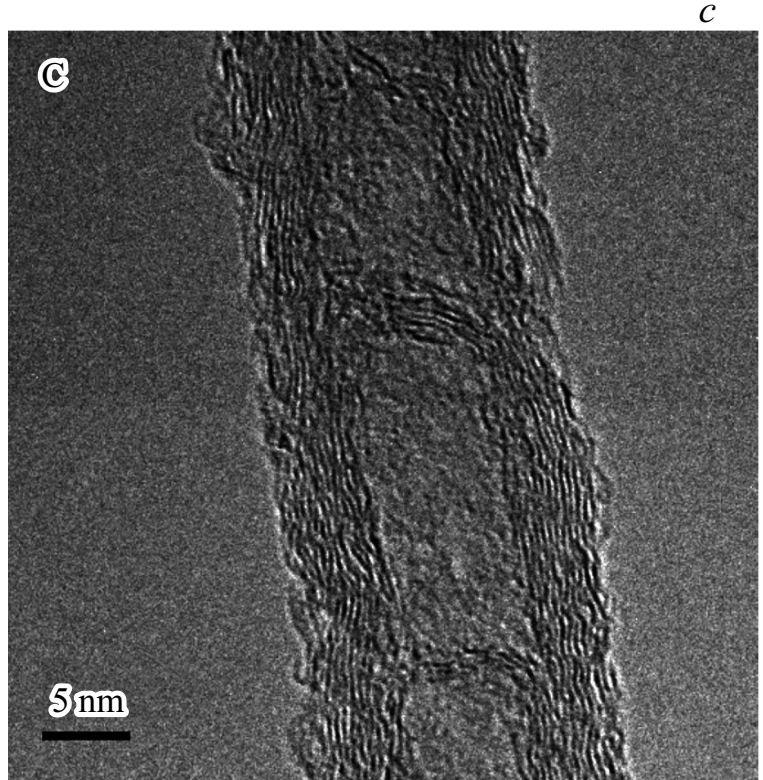

$b$

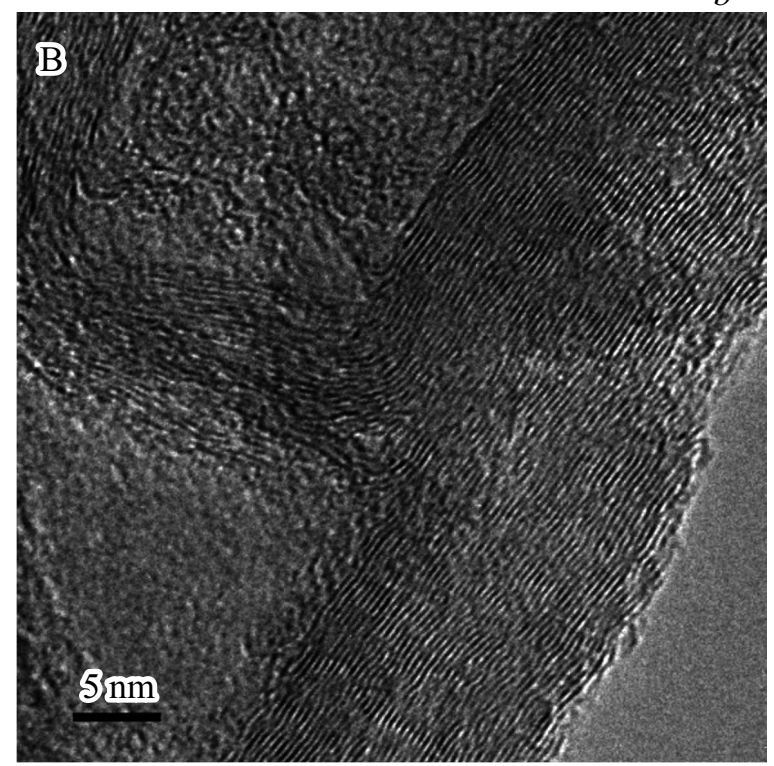

$d$

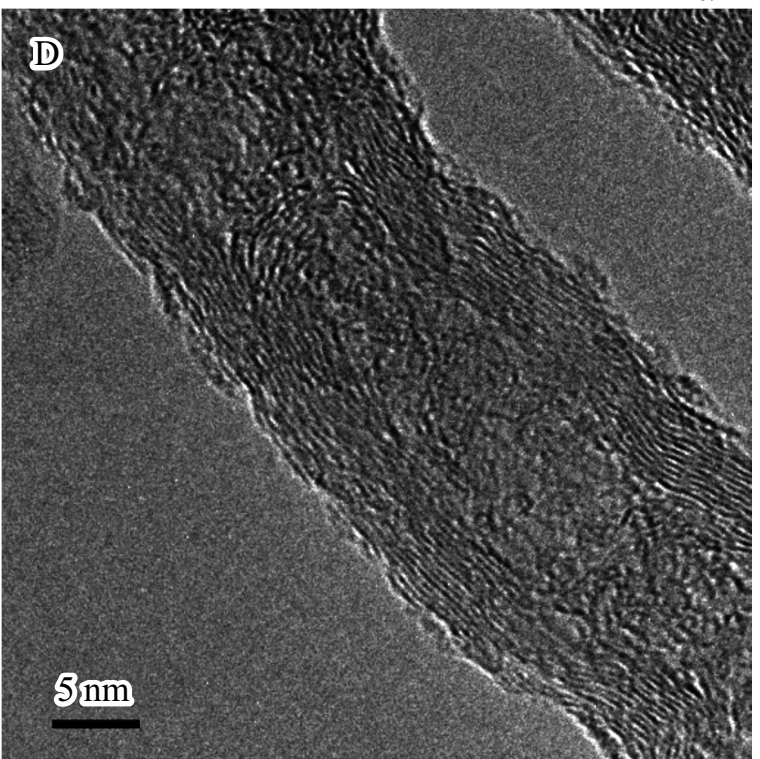

Рис. 5. ПЭМ-изображения: $(a)$ - МУНТ после облучения $\mathrm{Ar}^{+} E=300 \mathrm{keV}, 10^{12} \mathrm{~cm}^{-2}$ и последующего отжига в инертной атмосфере при $900^{\circ} \mathrm{C}$; область В, выделенная на части $(a) ;(c)$ - область C, выделенная на части $(a) ;(d)$ - область D, выделенная на части $(a)$.

кости атомов углерода в направлении (100). Расчет $E^{b}$ проводился по следующей формуле

$$
E^{b}=\frac{\sum_{i=1}^{n} E_{i}^{0}-E^{T o t}}{n} .
$$

Здесь $E^{\text {Tot }}$ - общая энергия элементарной ячейки состоящей из $n$ атомов, $i=1,2, \ldots n-$ номер атома в ячейки, $E_{i}^{0}-$ энергия $i$-го атома в вакууме.

В табл. 1 приведены результаты расчетов средней удельной энергии связи структур содержащих различное количество вакансий и значение корругации графенового слоя.
Из данных табл. 1 видно, что с увеличением числа вакансий в кластере величина средней удельной энергии связи падает. Исключение составляют кластер из двух вакансий, который энергетически более выгоден, чем структура с одной вакансией и кластер из 18 вакансий, который энергетически более выгоден, чем структура с 16 вакансиями. Это связано с тем, в структуре с одной вакансией кластером из 16 вакансий есть атомы углерода, имеющие всего две связи. Тогда как атом углерода с тремя связями энергетически более выгоден. Из чего можно сделать вывод, что структуры с атомами углерода с двумя связями нестабильны и могут являться 


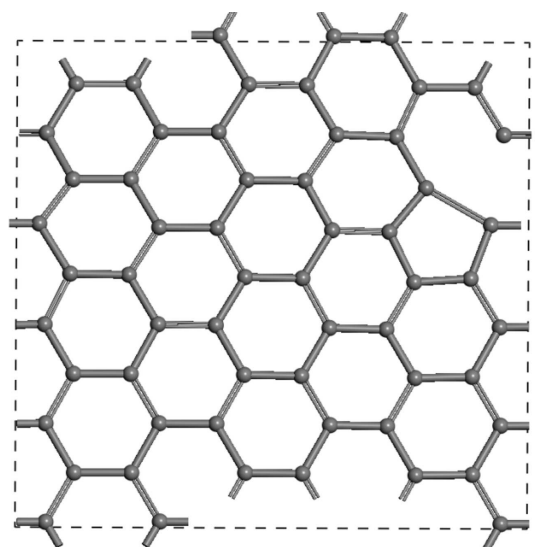

(001)

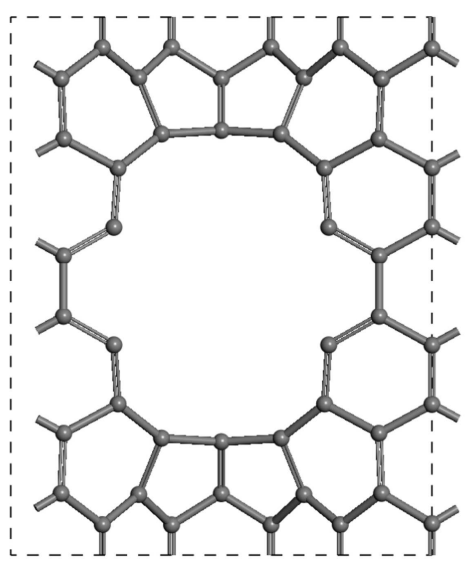

(001)

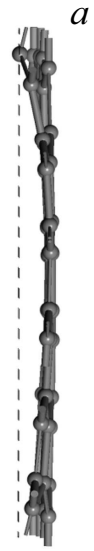

(100)

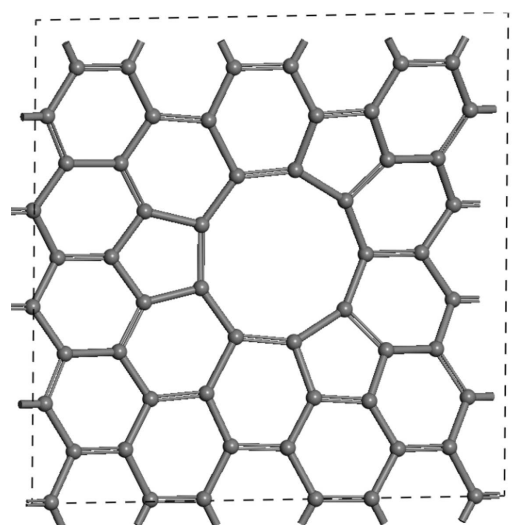

(001)

$c$

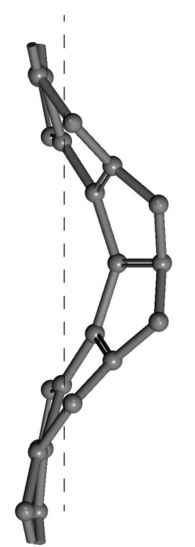

(100)

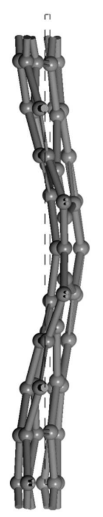

(100)

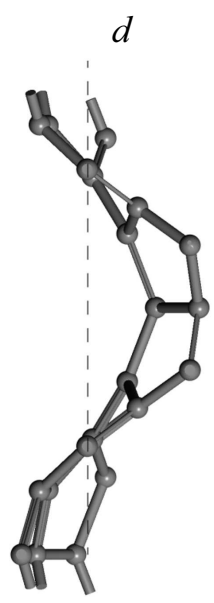

(100)

Рис. 6. Фрагменты оптимизированной структуры графеновых плоскостей (в направлении (001) слева и (100) справа) с дефектами типа вакансия. $(a)$ - одновакансионный дефект, $(b)$ - кластер из 4-х вакансий, $(c)$ - кластер из 14 вакансий, $(d)-$ кластер из 18 вакансий.

реакционными центрами. После заполнения свободной связи средняя удельная энергия связи должна возрасти. Также с увеличением размеров вакансионного кластера существенно увеличивается изгиб фрагмента графенового слоя, что, в конечном счете, должно приводить к изменению межслоевого взаимодействия в стенках МУНТ.

\section{3. Данные РФЭС}

Результаты количественного элементного анализа для МУНТ после различных обработок приведены в табл. 2.
Определение концентрации проводилось с использованием метода коэффициентов элементной чувствительности по обзорным РФЭС-спектрам, измеренным в диапазоне энергий связи 1000-0 eV.

Как видно из данных табл. 2 облучение МУНТ, как ионами аргона, так и электронами приводит к значительному увеличению концентрации кислорода в поверхностном слое массива. При этом в случае облучения аргоном концентрация кислорода увеличивается более значительно до 9.3 at.\% тогда как при облучении электронами наблюдается рост концентрации до 8.4 at.\%, несмотря на более высокую плотность тока электронов.

Таблица 1. Значения средней удельной энергии связи $E^{b}$ исследуемых структур и корругации фрагмента графенового слоя $h_{c}$, в зависимости от числа вакансий объединенных в кластер

\begin{tabular}{c|c|c|c|c|c|c|c}
\hline Число & 1 & 2 & 4 & 6 & 14 & 16 & 18 \\
\hline вакансий & & & & & 14 \\
$E^{\text {св }(\mathrm{eV})}$ & 9.31924 & 9.32564 & 9.26808 & 9.18003 & 8.88099 & 8.73116 & 8.86979 \\
$h_{c}(\AA)$ & 0.786 & 1.028 & 1.623 & 2.062 & 2.423 & 2.379 & 2.952
\end{tabular}



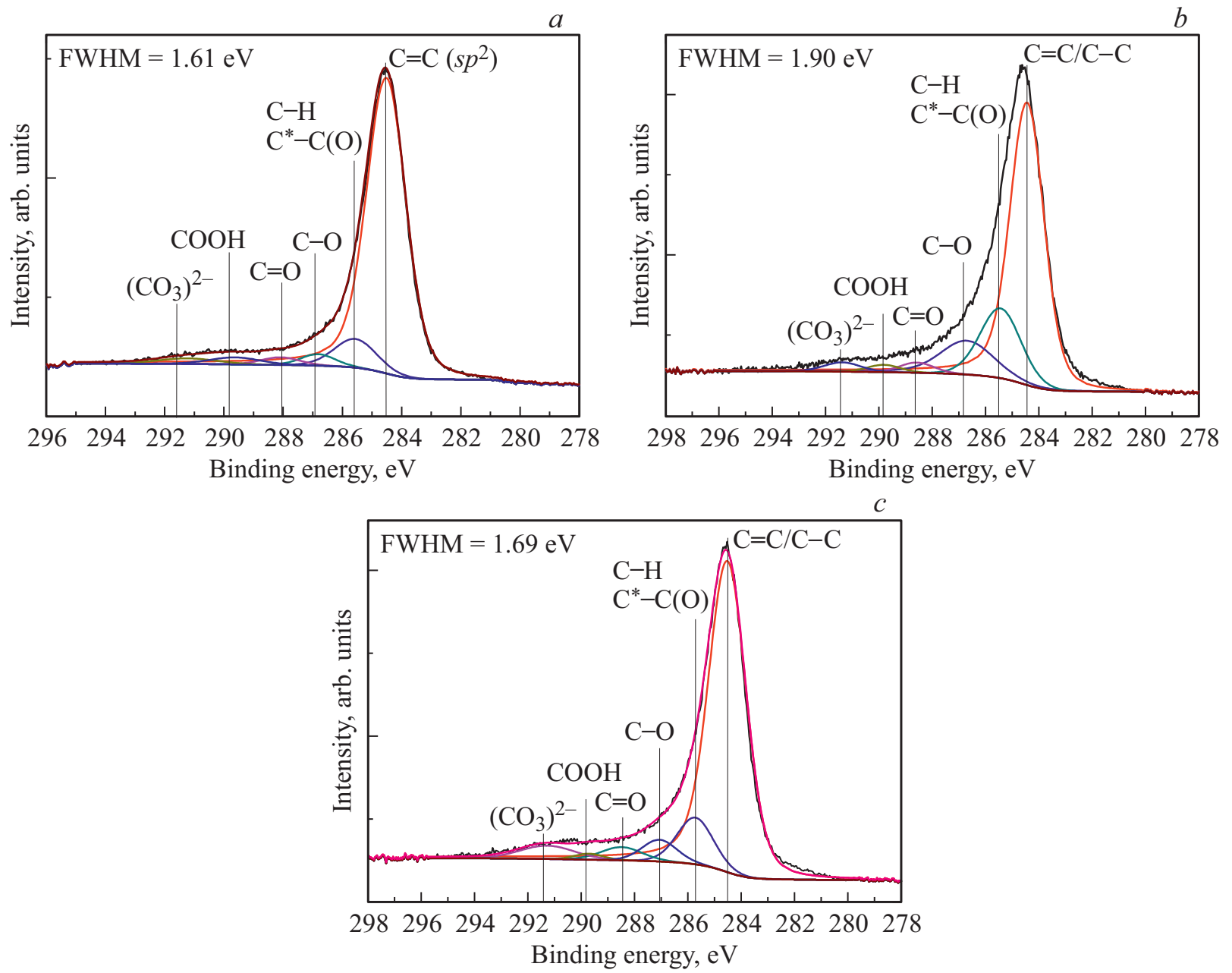

Рис. 7. РФЭС С $1 s$-спектры массивов МУНТ: $(a)$ - исходный; $(b)$ - после облучения ионами $\mathrm{Ar}^{+} E=300 \mathrm{keV}^{12} 10^{12} \mathrm{~cm}^{-2}$; (c) - после облучения ионами $\mathrm{Ar}^{+}$с последующей термообработкой.

Таблица 2. Результаты количественного элементного РФЭС анализа образцов

\begin{tabular}{l|c|c|c|c|c}
\hline \multirow{2}{*}{\multicolumn{1}{c|}{ Образец }} & \multicolumn{5}{|c}{ Концентрация, at.\% } \\
\cline { 2 - 6 } & {$[\mathrm{C}]$} & {$[\mathrm{N}]$} & {$[\mathrm{O}]$} & {$[\mathrm{Si}]$} & $\mathrm{Fe}$ \\
\hline Исходный & 95.6 & 3.1 & 1.3 & - & - \\
Облучение $\mathrm{e}^{-}$ & 89.5 & 2.1 & 8.4 & - & - \\
Облучение $\mathrm{e}^{-}+$отжиг & 92.2 & 1.4 & 6.1 & - & 0.3 \\
Облучение $\mathrm{Ar}^{+}$ & 88.3 & 2.4 & 9.3 & - & - \\
Облучение $\mathrm{Ar}^{+}+$отжиг & 90.9 & 2.1 & 6.0 & 1.0 & -
\end{tabular}

Рост концентрации кислорода обусловлен формированием структурных дефектов в стенках МУНТ и закреплением на данных дефектах функциональных кислородсодержащих групп различного состава $[18,19]$. Различия концентрации кислорода при облучении ионами аргона и электронами обусловлено, вероятно, различием количества и типов структурных дефектов, возникающих во время радиационной обработки. Облучение ионами аргона формирует как точечные, так и протяженные дефекты в структуре МУНТ, в то время как, электронное облучение генерирует преимущественно точечные и топологические дефекты. Последующая термообработка МУНТ приводит к снижению количества кислорода в составе образцов (до $\sim 6$ at.\%, см. табл. 2), что связано со снижением количества кислородных групп на поверхности МУНТ.

Анализ изменения структурно-химического состояния МУНТ в результате радиационной и последующей термической обработки, а также определение типов формирующихся функциональных групп проводилось путем детального изучения спектров остовных линий углерода (C $1 s)$.

На рис. 7 представлены результаты разложения на компоненты спектров массивов МУНТ после различных видов обработки. Наиболее интенсивный компонент спектров на энергии связи $\sim 284.6 \mathrm{eV}$ отвечает углероду, который входит в состав углерод-углеродных химических связей: $s p^{2}$-углероду, который формирует стенки MУНT $(\mathrm{C}=\mathrm{C})$, а также входящему в состав одинарных 

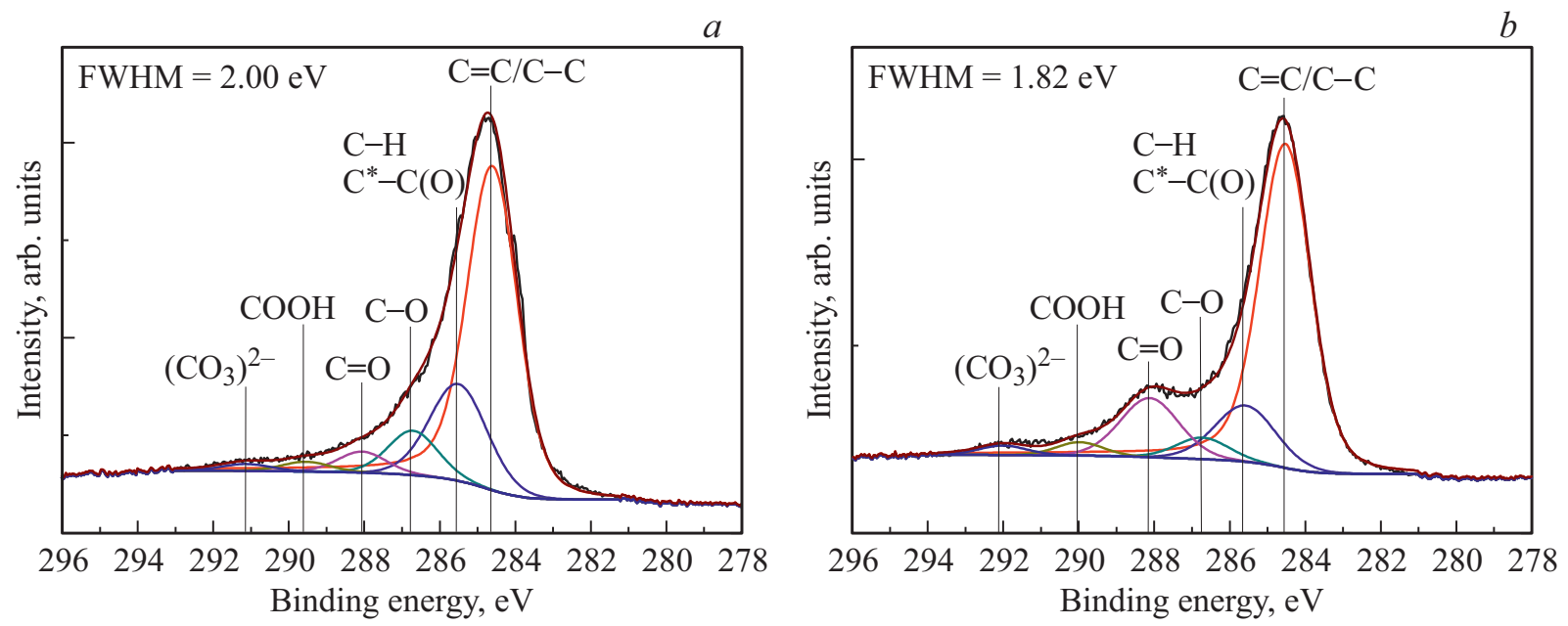

Рис. 8. РФЭС С $1 s$-спектры массивов МУНТ: $(a)$ - после облучения $\mathrm{e}^{-} E=3 \mathrm{MeV}, 10^{16} \mathrm{~cm}^{-2}$; $(b)-$ после электронного облучения с последующей термообработкой.

С-С-связей, присутствующих в стенках МУНТ в виде дефектов структурного строения. Компонент спектров $\mathrm{C} 1 s$ на энергии связи $\sim 285.5 \mathrm{eV}$ соответствует гидрогенизированному углероду $(\mathrm{C}-\mathrm{H})$, а также атомам углерода, расположенным непосредственно вблизи с окисленным углеродом $\left(\mathrm{C}^{*}-\mathrm{C}(\mathrm{O})\right)$. Компонент с максимумом на энергии связи отвечает одинарным C-O-связям в составе эпоксидных, гидроксидных, эфирных и др. функциональных групп. На энергиях связи $\sim 288$ и $289 \mathrm{eV}$ присутствуют состояния, отвечающие углероду в составе $\mathrm{C}=\mathrm{O}$ и $\mathrm{COOH} \mathrm{групп} \mathrm{соответственно} \mathrm{[19].}$ Наиболее высокоэнергетические состояния углеродного спектра на энергиях связи $\sim 291.5 \mathrm{eV}$ отвечают углероду в составе карбонатных групп $\left(\left(\mathrm{CO}_{3}\right)^{2-}\right)[20,21]$.

Из рис. 7, $b$ видно, что в спектре МУНТ после облучения наблюдается заметное увеличение параметра полуширины линии (FWHM), что указывает на более разнообразное химическое окружение углерода. Результаты разложения спектров на компоненты показывают, что наряду с этим наблюдается снижение относительной интенсивности компонента, отвечающего углеродуглеродным химическим связям $(\mathrm{C}=\mathrm{C} / \mathrm{C}-\mathrm{C})$. Его доля снижатся с $\sim 84 \%$ (для исходных МУНТ) до $\sim 66 \%$ после облучения ионами аргона. При этом, увеличивается содержание углерода, химически связанного с кислородом, а также доля атомов углерода находящихся вблизи функциональных групп.

После проведения термообработки в РФЭС спектре МУНТ облученных ионами аргона (рис. 7,c) доля углеродных химических связей $(\mathrm{C}=\mathrm{C} / \mathrm{C}-\mathrm{C})$ возрастает до $\sim 78 \%$. Также наблюдается уменьшение FWHM до $1.68 \mathrm{eV}$. Это свидетельствует о том, что термообработка приводит к частичному восстановлению графеновой структуры в стенках МУНТ, однако некоторая часть структурных дефектов, по-видимому, сохраняется. Также в РФЭС спектре облученных аргоном МУНТ с последующей термообработкой наблюдается снижение компонентов, связанных с окисленными формами углерода, что согласуется с результатами количественного элементного анализа (табл. 2).

На рис. 8 представлены спектры C $1 s$ массивов МУНТ после облучения электронами и отжига в инертной атмосфере при $900^{\circ} \mathrm{C}$. Аналогично случаю облучения ионами $\mathrm{Ar}$, в спектрах МУНТ после облучения электронами наблюдается увеличение полуширины линии C $1 s$ до $2 \mathrm{eV}$, а также уменьшение относительной интенсивности компонента, отвечающего углеродуглеродным связям $(\mathrm{C}=\mathrm{C} / \mathrm{C}-\mathrm{C} \sim 284 \mathrm{eV})$ с $\sim 88$ до $\sim 66 \%$, что указывает на увеличение дефектности нанотрубок (рис. 8,a). Также наблюдается увеличение относительной интенсивности компонент отвечающих углероду, химически связанному с кислородом (C-O $\sim 286.5 \mathrm{eV}, \mathrm{C}=\mathrm{O} \sim 288 \mathrm{eV})$, а также атомам углерода находящихся вблизи функциональных групп $(285.5 \mathrm{eV})$.

Отжиг в инертной среде приводит к восстановлению графеновой структуры МУНТ о чем свидетельствует рост интенсивности компонента $\mathrm{C}=\mathrm{C} / \mathrm{C}-\mathrm{C}$ с $\sim 66 \%$ после облучения до $\sim 68 \%$ после отжига (рис. $8, b)$. Также наблюдается снижение компонента $\mathrm{C}^{*}-\mathrm{C}(\mathrm{O})$ c $\sim 19$ до $\sim 12 \%$. При этом наблюдается перераспределение интенсивностей компонентов, отвечающих $\mathrm{C}-\mathrm{O}$ и $\mathrm{C}=\mathrm{O}$ химическим связям кислорода и углерода. После отжига относительная интенсивность компонента, соответствующего С-О-связи, уменьшилась с $\sim 7$ до $\sim 4 \%$. В то же время относительная интенсивность компонента $\mathrm{C}=\mathrm{O}$ увеличилась $\mathrm{c} \sim 3.5$ до $\sim 12 \%$. При этом, по данным количественного анализа (табл. 2), общая концентрация кислорода в МУНТ, облученных электронами и прошедших отжиг, уменьшилась с $\sim 8.4$ до $\sim 6$ at.\%.

Высокая плотность тока электронов и энергия во время облучения формирует в структурнее МУНТ большое количество точечных дефектов. Отжиг в инертной среде сопровождается миграцией междоузельных 
атомов, что приводит к восстановлению графеновой структуры стенок МУНТ за счет рекомбинации вакансий и междоузлий. Помимо миграции междоузельных атомов углерода, обладающих высокой подвижностью в стенках МУНТ, возможна и миграция вакансий, на что указывают авторы теоретических исследований [14-16]. При этом вакансионные дефекты способны взаимодействовать друг с другом с образованием мультивакансионных кластеров. Наличие таких кластеров и наблюдается на ПЭМ изображениях МУНТ после электронного облучения и последующего отжига в инертной среде. Данные математического моделирования указывают на реакционную активность мультивакансионных кластеров за счет наличия неспаренных электронов в химических связях углерода. Также известно что большинство кислород содержащих групп неустойчивы при температурах выше $500^{\circ} \mathrm{C}[22,23]$. Таким образом, наиболее вероятно, что процесс образования кислород-углеродных связей происходит при последующем контакте термообработанных МУНТ с атмосферой. Увеличение количества кислорода образующего двойную связь с углеродом, вероятно, связано с наличием большого количества границ графеновых слоев образованных мультивакансионными кластерами. Известно [14], что образование двойной химической связи углерода и кислорода происходит преимущественно на зигзагообразных границах графеновых слоев на „висячих“ атомах углерода.

\section{4. Заключение}

Исследования МУНТ, подверженных облучению ионами аргона и электронами, показало, что облучение приводит к формированию в стенках нанотрубок структурных дефектов. Данные ПЭМ показывают различие в структуре для нанотрубок облученных ионами аргона и электронами. Для МУНТ, облученных ионами аргона, наблюдается частичная аморфизация стенок и увеличение межслоевого расстояния до $\sim 0.37 \mathrm{~nm}$. Облучение электронами, в свою очередь, образует множество точечных дефектов, которые формируют разрывы во внешних графеновых слоях. При этом значение межплоскостного расстояния увеличивается до $\sim 0.39 \mathrm{~nm}$. Данные численного моделирования указывают на увеличение корругации фрагмента графенового слоя с увеличением размеров вакансионного кластера.

Отжиг в инертной среде при температуре $900^{\circ} \mathrm{C}$ приводит к существенно различным изменениям структуры для МУНТ, облученных ионами аргона и электронами. Нанотрубки, облученные ионами аргона, после отжига частично восстанавливают свою структуру. По данным ПЭМ наблюдается уменьшение межслоевого расстояния до $\sim 0.35 \mathrm{~nm}$. Данные, полученные из спектров РФЭС, указывают на уменьшение концентрации кислорода. В тоже время для нанотрубок, облученных электронами с последующим отжигом в инертной среде, данные ПЭМ указывают на существенные структурные изменения. Во внешних графеновых слоях присутствуют разрывы, в результате чего стенка МУНТ приобретает ломаный вид. Данные РФЭС указывают на уменьшение общей концентрации кислорода, но при этом наблюдается рост количества углерода в составе двойных углеродкислородных связей $(\mathrm{C}=\mathrm{O})$. Различия в структуре и химическом составе поверхности углеродных нанотрубок, подверженных облучению ионами и электронами, во время отжига обусловлено различием концентрации, а также типов структурных дефектов в стенках МУНТ, формирующихся в процессе облучения.

Полученные результаты свидетельствуют о том, что комбинация методов радиационного воздействия и последующего отжига в инертной среде может успешно использоваться в качестве способа функционализации МУНТ. Варьирование режимов облучения и термообработки может обеспечить возможность настройки структуры и свойств ансамблей и индивидуальных нанотрубок в широком диапазоне за счет избирательной функционализации поверхности МУНТ.

\section{Благодарности}

Авторы выражают благодарность Ю.А. Стенькину, М.В. Тренихину и Г.Н. Камаеву за синтез МУНТ и помощь в проведении экспериментов.

\section{Финансирование работы}

В работе было использовано оборудование Омского регионального центра коллективного пользования СО РАН. Работа выполнена по государственному заданию ОНЦ СО РАН в соответствии с Программой ФНИ ГАН на 2013-2020 годы (номер госрегистрации проекта в системе ЕГИСУ НИОКТР АААА-А17-117041210227-8).

\section{Конфликт интересов}

Авторы заявляют, что у них нет конфликта интересов.

\section{Список литературы}

[1] Г.С. Иванченко, Н.Г. Лебедев. ФТТ 51, 2281 (2009).

[2] В.В. Болотов, В.Е. Кан, П.М. Корусенко, С.Н. Несов, С.Н. Поворознюк, И.В. Пономарева, В.Е. Росликов, Ю.А. Стенькин, Р.В. Шелягин, Е.В. Князев. ФТТ 54, 154 (2012).

[3] И.В. Запороцкова, Н.П. Борознина, Ю.Н. Пархоменко, Л.В. Кожитов. Изв. вузов. Материалы электронной техники 5, 21 (2017).

[4] V.V. Bolotov, P.M. Korusenko, S.N. Nesov, S.N. Povoroznyuk, E.V. Knyazev. Nucl. Instrum. Meth. Phys. Res. 337, (2014).

[5] Shuang-Xi Xue, Qin-Tao Li, Xian-Rui Zhao, Qin-Yi Shi, ZhiGang Li, Yan-Ping Liu. J. Nanomater. 2014, 313095 (2014).

[6] O. Lehtinen, T. Nikitin, A.V. Krasheninnikov, L. Sun, F. Banhart, L. Khriachtchev, J. Keinonen. New J. Phys. 13, 073004 (2011). 
[7] Reetu Kumari, Fouran Singh, Brajesh S. Yadav, Ravinder K. Kotnala, Koteswara Rao Peta, Pawan K. Tyagi, Sanjeev Kumar, Nitin K. Puri. Nucl. Instrum. Meth. Phys. Res. B 412, 115 (2017).

[8] H.R. Adam. Palser. Phys. Chem. Chem. Phys. 1, 4459(1999).

[9] V.V. Bolotov, V.A. Volodin, G.N. Kamayev, V.Ye. Kan, Ye.V. Knyazev, V.A. Sachkov. AIP Conf. Proc. 2007, 040002 (2018); doi: 10.1063/1.5051929.

[10] A. Figaro, J. Pourchez, D. Boudard, V. Forest, S. Berhanu, J.-M. Tulliani, J.-P. Lecompte, M. Cottier, D. Bernache-Assollant, Ph. Grosseau. J. Nanopart. Res. 17, 194 (2015).

[11] Е.В. Князев, В.В. Болотов, К.Е. Ивлев, С.Н. Поворознюк, В.Е. Кан, Д.В. Соколов. ФТТ 61, 564 (2019).

[12] J.P. Perdew, K. Burke, M. Ernzerhof. Phys. Rev. Lett. 100, 136406 (2008).

[13] Z. Xu, L. Xu, F. Fang, H. Gao, W. Li. Nucl. Instrum. Meth. Phys. Res. B 307, 203 (2013).

[14] J.Y. Huang, S. Chen, Z.F. Ren, Z.Q. Wang, D.Z. Wang, M. Vaziri, Z. Suo, G. Chen, M.S. Dresselhaus. Phys. Rev. Lett. 97, 075501 (2006).

[15] A.V. Krasheninnikov, P.O. Lehtinen, A.S. Foster, R.M. Niemien. Chem. Phys. Lett. 418, 132 (2006).

[16] Ch. Jin, K. Suenaga, S. Iijima. Nano Lett. 8, 1127 (2008).

[17] J.Y. Huang, S. Chen, Z.F. Ren, Z.Q. Wang, D.Z. Wang, M. Vaziri, Z. Suo, G. Chen, M.S. Dresselhaus. Phys. Rev. Lett. 97, 075501 (2006).

[18] K. Bogdanov, A. Fedorov, V. Osipov, T. Enoki, K. Takai, T. Hayashi, V. Ermakov, S. Moshkalev, A. Baranov. Carbon 73, 78 (2014).

[19] С.Н. Несов, П.М. Корусенко, В.В. Болотов, С.Н. Поворознюк, Д.А. Смирнов. ФТТ 10, 2006 (2017).

[20] L.G. Bulusheva, S.G. Stolyarova, A.L. Chuvilin, Y.V. Shubin, I.P. Asanov, A.M. Sorokin, A.V. Okotrub. Nanotechnology 29, 134001 (2018).

[21] P. Bazylewski, D.W. Boukhvalov, A.I. Kukharenko, E.Z. Kurmaev, A. Hunt, A. Moewes, G.S. Chang. RSC Advances 5, 75600 (2015). doi: 10.1039/c5ra12893e

[22] I. Mazov, V.L. Kuznetsov, I.A. Simonova, A.I. Stadnichenko, A.V. Ishchenko, A.I. Romanenko, E.N. Tkachev, O.B. Anikeeva. Appl. Surf. Sci. 258, 6272 (2012).

[23] Д.А. Усанов, А.В. Скрипаль, А.В. Романов. ЖТФ 84, 86 (2014).

Редактор Ю.Э. Китаев 